\title{
TRIBUTOS AMBIENTALES: LA APLICACIÓN COORDINADA DE LOS PRINCIPIOS QUIEN CONTAMINA PAGA Y DE CAPACIDAD CONTRIBUTIVA
}

\author{
ENVIRONMENTAL TAXES: THE COORDINATED APLICATION OF THE \\ POLLUTER-PAYS AND ABILITY TO PAY PRINCIPLES
}

\author{
Rodolfo Salassa Boix ${ }^{1}$
}

\begin{abstract}
RESUMEN: El presente trabajo propone una armoniosa convivencia entre los principios contaminador-pagador y de capacidad contributiva cuando se aplican en el ámbito de los tributos ambientales y, a partir de allí, pretende responder a una serie de interrogantes prácticos relacionados con la creación y aplicación de dichos tributos.
\end{abstract}

Palabras clave: Hacienda pública, extrafiscalidad, tributos ambientales, principio quien contamina paga, principio de capacidad contributiva.

ABSTRACT: This paper propose a balanced coexistence between the polluter-pays and the ability to pay principles when they are applied within the field of an environmental tax and, thereafter, to attempts to answer some practical questions related to the creation and application of that kind of tax.

Key words: Public finances, non-fiscal purposes, environmental taxes, polluter-pays principle, ability to pay principle.

\section{INTRODUCCIÓN Y PLANTEO DEL PROBLEMA}

Los tributos ambientales constituyen una de las tantas medidas con las que cuentan los gobiernos para proteger el medio ambiente a los fines de detener, o al menos reducir, los devastadores efectos derivados de la contaminación. Concretamente, podemos definir a estos tributos como aquellos gravámenes que, sin despojarse de su finalidad recaudatoria, tienen como principal objetivo direccionar la conducta de los administrados para desincentivar la realización de actividades perniciosas para el medio ambiente, sin perjuicio del destino de los fondos recaudados ${ }^{2}$. A pesar de su carácter ambiental estos instrumentos son

\footnotetext{
1 Abogado, Licenciado en Derecho por la Universidad Nacional de Córdoba, Argentina (UNC), Magíster en Derecho de la Empresa y la Contratación (mención europea) y Doctor en Derecho (doctorado europeo) por la Universidad Rovira i Virgili de Tarragona, España (URV). Investigador del Consejo Nacional de Investigaciones Científicas y Tecnológicas de Argentina (CONICET). Profesor de grado y postgrado de Derecho tributario en la UNC y la URV. El presente trabajo se enmarca dentro del Proyecto de Investigación "La protección ambiental a través del sistema fiscal: una mirada jurídica interdisciplinar de los tributos ambientales en el marco de la normativa argentina” (período 2014-2015), dirigido por el Dr. Salassa Boix, aprobado por la Secretaría de Ciencia y Tecnología (UNC). Dirección postal: Caseros 301, 1º piso, Córdoba Capital, Argentina (CP: 5000). Correo electrónico: rodolfoboix@hotmail.com

2 Salassa Boix (2013) p. 186.
} 
verdaderos gravámenes, aunque su finalidad principal ya no es recaudatoria sino más bien extrafiscal ${ }^{3}$.

Estamos ante una cuestión sumamente transversal, ya que su regulación involucra diversos campos científicos, tanto jurídicos como extrajurídicos ${ }^{4}$. En lo que respecta al ámbito estrictamente jurídico estos gravámenes presentan una íntima relación entre el Derecho ambiental y el Derecho tributario. Este carácter multidisciplinar se traduce en una convivencia de los principios propios de cada una de estas disciplinas jurídicas; sin ánimo de detenernos a analizar todos ellos nos abocaremos solo a dos. Respecto al Derecho ambiental destacamos el principio quien contamina paga (o principio contaminador-pagador) y respecto al Derecho tributario el principio de capacidad contributiva. Tomamos estos dos principios porque su convivencia no es del todo pacífica y su aplicación simultánea podría generar algunas contradicciones que, de no resolverse, dejarían sin sustento jurídico a muchos tributos ambientales peligrando incluso su constitucionalidad.

En virtud de ello, el trabajo no pretende agotar toda la temática sobre los tributos ambientales sino solo proponer una armoniosa convivencia entre estos dos principios cuando se aplican en el ámbito de tales gravámenes y, a partir de allí, responder una serie de interrogantes prácticos relacionados con la creación y aplicación de aquellos. Concretamente, considerando los principios en juego nos planteamos las siguientes preguntas:

1) ¿Es técnicamente adecuado legislar un tributo ambiental cuyo hecho imponible grave conductas o bienes ecológicamente irrelevantes?

2) ¿Es técnicamente adecuado legislar un tributo ambiental cuyo hecho imponible grave conductas o bienes ecológicamente relevantes pero el contaminador no goza de capacidad contributiva?

3) ¿Qué límites se derivan de los principios bajo análisis a la hora de regular un tributo ambiental?

A los fines de abordar el tema propuesto y resolver los interrogantes planteados estructuramos el trabajo en tres partes. Las dos primeras están dedicadas a desarrollar cada uno de los principios bajo análisis y su relación con los gravámenes ecológicos. La tercera parte está abocada a las conclusiones del trabajo y a la resolución de los interrogantes.

Por cuestiones de extensión el trabajo se enfoca esencialmente sobre la normativa argentina, aunque con algunas referencias específicas a otros ordenamientos jurídicos. No obstante, el contenido general y sus conclusiones van más allá del Derecho argentino, trascendiendo prácticamente a cualquier tributo ambiental. Mucho más si se trata de países como Chile con el que compartimos la misma tradición doctrinal en material fiscal.

\footnotetext{
3 En el diseño de un tributo ambiental lo primero es que desaliente actividades contaminantes. FULLERTON (1996) p. 36.

4 El medio ambiente es un bien complejo, pues está integrado por diversos elementos interrelacionados en un todo unitario. Herrera Molina (2000) pp. 23-188.
} 


\section{PRINCIPIO QUIEN CONTAMINA PAGA}

\section{ORIGEN Y RECEPCIÓN NORMATIVA}

El principio quien contamina paga, originado en el ámbito de las ciencias económicas y adoptado luego por el Derecho ambiental, es la directriz que orienta gran parte de los instrumentos de protección ecológica. Una de sus primeras apariciones normativas se remonta a la Enmienda japonesa de 1970, según la cual las empresas contaminantes eran económicamente responsables por los daños producidos a la comunidad ${ }^{5}$. No obstante, su proyección internacional se debe fundamentalmente a dos Recomendaciones de la Organización para la Cooperación y el Desarrollo Económico (OCDE) de 1972 y 1976.

En una primera instancia tenemos la Recomendación de la OCDE del 26 de mayo de 1972, que decía lo siguiente:

"El contaminador debe soportar los costos de llevar a cabo las medidas decididas por los poderes públicos para alcanzar un estado aceptable del medio ambiente. En otras palabras, el coste de dichas medidas debería reflejarse en el costo de los bienes y servicios que causen la polución a través de su producción y/o consumo. Cada medida no será acompañada por subsidios que creen distorsiones significativas en el comercio internacional y en la inversión".

La necesidad de reconocer este principio se basa en el hecho que "el aprovechamiento de los bienes comunes como bienes libres desde el punto de vista de su utilización, y gratuitos en cuanto a su costo de uso o explotación, ha conducido a un creciente deterioro del medio ambiente" 7 .

No mucho tiempo después, el 21 de noviembre de 1974, el mismo organismo emitió una nueva Recomendación reafirmando los términos de su antecesora y dando algunas pautas prácticas sobre su implementación. Entre otras cuestiones estableció que se trata de un "principio fundamental para asignar los costos de las medidas de prevención y control de la contaminación, introducidas por las autoridades públicas de los países miembros” y recalcó sobre "la necesidad de aplicar uniformemente este principio a través de la adopción de una base común para las políticas ambientales de los países miembros".

Desde que la OCDE lo enunció y ratificó el principio no demoró en convertirse en uno de los pilares del Derecho ambiental internacional y en ser receptado por diferentes ámbitos normativos. No obstante, su consagración internacional definitiva se plasmó en el conocido Principio 16 de la Declaración de Río sobre el Medio Ambiente y Desarrollo de 1992 (DRMAD), que expresa lo siguiente: "Las autoridades nacionales deberían procurar fomentar la internalización de los costos ambientales y el uso de instrumentos económicos, tendido en cuenta el criterio de que el que contamina debería, en principio, cargar con los costos de la contaminación, teniendo debidamente en cuenta el interés público y sin distorsionar el comercio ni las inversiones internacionales".

5 KARAN (2005) p. 359.

6 Recordemos que en el año 2010 Chile se convirtió en el primer y único país sudamericano miembro de la OCDE.

7 Valenzuela (1991) p. 12. 


\section{NOCIÓN Y CONTENIDO}

\subsection{Introducción}

Fijar el contenido y alcance de este principio resulta una tarea compleja. Autores como García López sostienen que "el significado jurídico del principio quien contamina paga sigue sin estar definido" y que "todavía presenta márgenes de indefinición jurídica, tanto a nivel nacional, como comunitario e internacional", por tanto, no queda claro si estamos ante un "objetivo a alcanzar" o "un principio jurídico autónomo" en materia ambiental $^{8}$. Estas confusiones han generado que más allá de su extendida aplicación pocos autores le otorguen al principio un alcance concreto, lo que deriva, a su vez, en que se haya difundido mucho más su denominación que su contenido?.

Muchos juristas se han visto tentados a explicar el principio a través de una visión literal y sumamente simplista que parte de la mera unión de los verbos de su enunciado. Tomando las expresiones "contamina" y "paga" se lo ha entendido como aquella máxima por medio de la cual quien haya realizado un acto contaminante debe asumir su costo. Esta idea no es errónea pero se enmarca en una interpretación restrictiva y simplificada que no alcanza a reflejar todo su alcance, mucho menos cuando de tributos ambientales se trata. Es prácticamente imposible definir y otorgarle contenido al principio quien contamina paga basándose exclusivamente en una visión literal.

A falta de una definición normativa del término "contaminar" debemos recurrir al Diccionario de la Real Academia Española. Dicho término significa "alterar nocivamente la pureza o las condiciones normales de una cosa o un medio por agentes químicos o físicos". Al hablar del medio ambiente podemos decir que se trata de cualquier modificación, de carácter negativo, de las condiciones normales o naturales de aquel. Las condiciones normales del medio ambiente serían aquellas que se desarrollan cuando no existe ningún tipo de interferencia humana, es decir, el estado natural y propio del entorno ecológico (no humano) que nos rodea. Pero no toda alteración es negativa, y acá es donde estriba la clave del concepto. Vemos también que la definición nada dice sobre la relevancia o magnitud de tal alteración, erigiéndose así en una noción sumamente amplia que resulta a todas luces insuficiente para dotar de contenido al principio bajo estudio.

De esta definición se sigue entonces que no habrá contaminación cuando no se alteren las condiciones normales del medio ambiente o cuando la alteración de dichas condiciones sea de carácter positivo (v.g. reforestando un descampado). A partir de ello se advierte que la gran mayoría de las actividades humanas genera, de una forma u otra, de manera más o menos significativa, algún efecto contaminante. Por lo tanto, siguiendo al pie de la letra el enunciado del principio, casi todo obrar humano debería pagar por la contaminación que genera. Pero esto no es lo que realmente quiere decir dicho principio.

Resulta útil recurrir el principio del desarrollo sostenible ${ }^{10}$, el cual considera que el crecimiento económico es valioso y debe promoverse siempre que pueda ser mantenido en

\footnotetext{
8 García lópez (2001) p. 63.

9 Fuentes Olivares (1999) p. 25.

10 Principio 3 de la DRMAD.
} 
el tiempo sin menguar los recursos y las oportunidades de las generaciones futuras. Cuando conjugamos el principio de desarrollo sostenible con el principio contaminador pagador advertimos que no se pretende erradicar todo tipo de contaminación, ya que se truncaría casi cualquier posibilidad de crecimiento de la economía, sino aquella que implique llevar adelante un avance económico insostenible ${ }^{11}$. Esto nos mueve a hablar de diferentes niveles de contaminación, entre los cuales habrá un punto en el que esta pasará de ser tolerable a no serlo, y ese será el límite a partir del cual la actividad contaminante debe eliminarse o prohibirse. En este planteo el concepto de relevancia adquiere vital importancia.

Así como se habla de un estado aceptable o inaceptable del medio ambiente se puede hablar, como contrapartida, de un estado aceptable o inaceptable de la contaminación. El criterio para determinar la tolerancia o no de un acto contaminante y, por ende, su aceptación se encuentra en el principio de desarrollo sostenible: será tolerable la contaminación que no ponga en juego la equidad intergeneracional de los recursos naturales. Ello requiere de un profundo análisis del impacto ambiental de cada actividad.

Si hurgamos un poco en el término "contaminar" advertimos que no toda contaminación, en el sentido antes expuesto, genera estrictamente la obligación de pagar por ella. Esto no quiere decir que el principio no sirva o no se aplique sino que hay que realizar un análisis mucho más profundo para dimensionar su alcance real. A su vez, si vemos la definición del principio en la DRMAD dice que "quien contamina debe, en principio, cargar los costos de la contaminación”. Al decir "en principio" está indicando que en ciertas ocasiones las actividades contaminantes no tendrán la consecuencia señalada (el pago), la cuestión radica en determinar en qué casos ocurrirá tal cosa. Reiteramos que la clave está en la relevancia de la contaminación.

Las confusiones sobre el alcance del principio también se ven alimentadas cuando tomamos la expresión "paga”. Según la explicación de la DRMAD el pago es la consecuencia que conlleva la realización de actividades contaminantes, ya que quien contamina debe “...cargar con los costos de la contaminación”. Determinar a qué se refiere esta norma con "los costos de la contaminación" es adentramos en un terreno espinoso y poco diáfano. En primer lugar, si nos ceñimos al enunciado del principio no sabemos si solo se refiere un resarcimiento económico, si incluye a las sanciones económicas o incluso si también contempla, siempre que sea posible, la recomposición de la naturaleza al estado anterior a la contaminación. Asimismo, podríamos preguntarnos si una sanción no económica (v.g. prisión) quedaría fuera de este principio o si en realidad el término "paga" es utilizado en una acepción más amplia.

Las limitaciones del lenguaje y la complejidad que encarnan los principios (en general) conllevan que sea prácticamente imposible inferir la noción y el contenido del principio quien contamina paga basándonos únicamente en su postulación. Su denominación es meramente orientativa y necesitamos de una explicación minuciosa y profunda para determinar su verdadero alcance, y ésa es nuestra tarea para las próximas páginas.

11 Los tributos ambientales constituyen herramientas para modificar conductas contaminantes aunque sin necesariamente impedir completamente las actividades que agreden al medio ambiente. DA SiLVA (2012) p. 5001. 


\subsection{Dimensiones del principio contaminador-pagador}

Una primera aproximación a este principio nos remite a la reparación de los daños ocasionados. Como sostiene Herrera Molina "se produce una simbiosis entre el nuevo principio (cuyos contornos jurídicos son aún difusos) y otras figuras de gran raigambre jurídica... en particular con la responsabilidad civil por daños ambientales"12. Pero, como veremos, su contenido va más allá de la mera responsabilidad y su función resarcitoria.

A los fines de comprender adecuadamente el contenido de este principio e identificar su relación con los tributos ambientales, es preciso analizarlo desde una triple dimensión: preventiva, reparadora/resarcitoria y sancionatoria. La importancia de este esquema estriba en organizar mejor su contenido y evitar así las limitaciones en las que muchos juristas han caído al definir este principio solo desde una dimensión.

a) Dimensión preventiva

Esta dimensión se vislumbra en los orígenes del principio, ya que la Resolución de la OCDE de 1974 aclara que estamos ante un "principio fundamental para asignar los costos de las medidas de prevención y control de la contaminación”. Tan o más importante es prevenir que recomponer, resarcir o sancionar la realización de daños ambientales. Bajo esta dimensión el principio promueve conductas con el objeto de prevenir daños ambientales, por lo cual se vislumbran dos subdimensiones bien diferenciadas: la persuasoria y la disuasoria.

La subdimensión persuasoria consiste en estimular medidas capaces de prevenir el acaecimiento de daños ambientales. Aquí se podría decir que no paga (o paga menos) quien realiza actividades que ayuden en alguna medida a evitar el maltrato ambiental significativo.

La subdimensión disuasoria, que la doctrina coincide en ubicar dentro la faceta preventiva de la responsabilidad por daños, también promueve la prevención del daño pero a través del desaliento de conductas perniciosas, por cuya realización se debe "pagar"13. La función preventiva del Derecho de daños es de corte disuasorio y “...se presenta como un complemento idóneo de las tradicionales vías resarcitorias... siendo que la prevención del daño es siempre preferible a su reparación" ${ }^{14}$. En el caso de la protección ambiental esta disuasión está enfocada lógicamente en las actividades antiecológicas. Desde esta perspectiva el principio intenta promover la utilización de instrumentos que desmotiven el uso inapropiado del medio ambiente, logrando que el costo real por tal uso sea asumido por quienes se benefician de las actividades contaminantes.

b) Dimensión reparadora

Una vez acaecido el daño ambiental se ha traspasado la barrera de la prevención y solo resta retornar las cosas al estado anterior, como si nada hubiera ocurrido, o indemnizar a la comunidad por los daños irreparables causados. Es aquí donde entra en juego esta

\footnotetext{
12 Herrera Molina (2000) p. 41.

13 Espinoza Espinoza (2007) p. 54.

14 Pizarro y Vallespinos (1999) p. 462.
} 
dimensión, ya que el daño ambiental debe ser reparado o, de no ser posible, resarcirse a la sociedad.

Hasta aquí cuando hemos hablado de resarcimiento lo hicimos desde lo que se conoce como "resarcimiento sancionatorio", que tradicionalmente ha sido planteado por la corriente clásica de la teoría de la responsabilidad por daños y está ligado indisolublemente a la noción de antijuricidad. En nuestro caso, la antijuricidad se refiere al hecho que el daño ambiental, o la actividad que lo causa, hayan estado prohibido por la normativa.

Pero la vertiente más moderna de la teoría de la responsabilidad por daños ha sumado al resarcimiento sancionatorio la noción de resarcimiento distributivo. Esa nueva perspectiva del resarcimiento se refiere a la responsabilidad por los daños que provienen de conductas lícitas, cuando el ordenamiento jurídico, por diferentes razones, los pone a cargo de un tercero o decide solidarizarlos y asignarlos a toda o gran parte de la sociedad ${ }^{15}$.

\section{c) Dimensión punitiva}

En esta dimensión el principio procura aplicar sanciones, administrativas o penales, a quienes hayan realizado un daño ambiental. En el caso de las penas económicas ya no se trata tanto de resarcir a la comunidad por el perjuicio ecológico causado sino de castigar al infractor o delincuente, a la vez que desalentar al resto de la sociedad a la realización de tales conductas.

\subsection{Las dimensiones del principio contaminador-pagador y los tributos ecológicos}

Respecto a la dimensión punitiva recordemos que las sanciones presuponen haber cometido previamente una infracción, en cambio los tributos presuponen haber realizado un hecho generador, que nunca puede ser tomado como una infracción. Los tributos no persiguen una finalidad sancionatoria debido a la diversa función que tienen respecto de las sanciones. Estas no pretenden repartir las cargas públicas sino simplemente prevenir o reprimir un comportamiento negativamente valorado por el ordenamiento jurídico ${ }^{16}$. En definitiva, "el binomio infracción-sanción no se muestra adecuado para regular tales situaciones" 17 .

En cuanto a la dimensión reparadora/resarcitoria, en primer lugar, los tributos ambientales no persiguen retornar el statu quo ante sino desmotivar la realización de conductas antiecológicas, razón por la cual no tienen a priori una función reparadora ${ }^{18}$. En segundo lugar, tampoco son encuadrables dentro del "resarcimiento sancionatorio", ya que este consiste en la reacción ante un hecho ilícito que, al generarse un daño, busca indemnizar a los afectados. Un tributo ambiental nunca presupone la comisión de un hecho ilícito sino la realización un hecho generador. De hecho, "la noción de equivalencia indemnizatoria... es

15 Pizarro y Vallespinos (1999) pp. 464-465.

16 FAnTOZZi (1998) pp. 41-42.

17 Varona Alabern (2010) p. 83.

18 Es irrelevante para los tributos ambientales que su recaudación sea destinada a retornar a la situación ambiental antes de que se produjera el daño ya que su esencia está en la desmotivación de conductas más que en el destino de sus fondos. 
en principio ajena a las obligaciones impositivas" ${ }^{19}$. En tercer y último lugar, la tributación ecológica tampoco gira en torno a la subdimensión "resarcitoria distributiva", ya que los riesgos y daños ambientales no se ponen a cargo de terceros ajenos ni sobre la sociedad en general. Los tributos ambientales, por definición, son aquellos gravámenes cuyo hecho imponible está directamente relacionado con la desmotivación de conductas antiambientales, de manera que un tributo cuyo hecho imponible no tenga esta finalidad podrá seguir siendo un gravamen pero dejará de tener una connotación ecológica.

En virtud de ello, los tributos ambientales se mueven dentro de la dimensión preventiva (subdimensión disuasoria) del principio contaminador-pagador ${ }^{20}$ que veremos a continuación.

\section{EL PRINCIPIO QUIEN CONTAMINA PAGA Y LOS TRIBUTOS AMBIENTALES}

El principio contaminador-pagador "persigue reflejar en el precio de las actividades y productos contaminantes las deseconomías externas causadas por el deterioro del medio ambiente" 21 , dicho de otra manera, se lleva al contaminador a internalizar los costos asociados a la producción o el consumo ${ }^{22}$. Se pretende asegurar la eficiencia económica por medio de la integración de dichos costes en los precios, buscando así disminuir la cantidad de contaminación ${ }^{23}$.

Según la teoría económica una externalidad es una situación en la cual "la decisión de un agente económico produce efectos en otros agentes, siempre que esa decisión no genere un precio de mercado como compensación" 24 . El concepto de "externalidad" se ilustra mejor si hablamos de "efectos externos", entendidos como los beneficios o costos que son recibidos por las personas que no están implicadas en la realización de una determinada actividad $^{25}$.

Los efectos externos positivos (o externalidades positivas) son aquellos que producen un beneficio social o aumentan el bienestar de otros agentes sin que su generador reciba retribución alguna ( $v . g$. la transformación de un basural en un parque o la reforestación de un descampado). Los efectos externos negativos (o externalidades negativas) son aquellos que producen un perjuicio social o reducen el bienestar de otros agentes sin que estos

\footnotetext{
19 Rozo Gutiérrez (2003) pp. 182-183.

20 Esta misma conclusión ya había sido esbozada en OCDE (2001) p. 9. En dicha oportunidad se dijo que los tributos ambientales respetan la esencia del principio contaminador-pagador ya que implican asumir los costos que conlleva la prevención y el control de los daños ambientales.

21 Herrera Molina (2000) p. 40. En este mismo sentido se ha dicho que "cualquier actividad que provoca un daño ambiental crea una deseconomía externa, ya que impone a los terceros ajenos a la actividad lesiva algunos costos sociales de los que viene exonerado el sujeto agente del daño y que, en consecuencia, no los deberá contabilizar como propios al desarrollo de su actividad empresarial”. MuÑoz (2004) p. 163.

22 Desde una perspectiva económica el uso de instrumentos basados en el mercado se justifica por su capacidad para corregir las deficiencias del mercado de una forma rentable. Por deficiencia del mercado se entiende una situación en la que los mercados no existen o bien no tienen suficientemente en cuenta el coste «verdadero»o social de la actividad económica. Libro Verde (2007) p. 3.

23 VANDeKerckHove (1993) p. 204.

24 Morel (2010) p. 56.

25 Cámara de la Fuente (1993) p. 260.
} 
reciban compensación alguna. Al tomar decisiones y llevar adelante ciertas actividades perjudiciales para el medio ambiente los agentes económicos consideran los costos privados y los beneficios que recibirán, pero rara vez se detienen a calcular el costo social de la contaminación que generarán ${ }^{26}$ (v.g. la contaminación acústica o el esmog que producen los automóviles en una ciudad).

Los efectos externos negativos se refieren, en definitiva, a las ya mencionadas "deseconomías externas" y estas son las que nos interesan desde el punto de vista fiscal, ya que los tributos ambientales intentan solucionar tales fallas económicas. Concretamente, gravando ciertas conductas y actividades contaminantes se busca que sus generadores "internalicen" los costos sociales que producen las externalidades negativas que recaen sobre la sociedad. Al elevar (internalizar) los costos que implican ciertas actividades y el uso de bienes comunes, los tributos ambientales permiten disminuir su realización y utilización o promover la aplicación de procesos ecológicamente más eficientes ${ }^{27}$.

De esta forma se lleva adelante la función disuasoria del principio quien contamina paga. No obstante, es importante tener en miras el destino de los fondos recaudados, ya que si estos luego se dirigen a fomentar actividades contaminantes se habrá desvirtuado al principio contaminador-pagador ${ }^{28}$.

Este tema nos remite al debate entre PigOu y COASE sobre la elección de las políticas públicas ambientales frente a las deficiencias del mercado por externalidades que este no parece poder resolver. Hace ya más de ochenta años que los estudiosos de la ciencia económica ortodoxa hicieron eco de la presencia de una serie de deficiencias en el funcionamiento de la asignación de bienes, servicios y factores de producción a tal punto que los precios de muchos de esos objetos negociados no revelaban su verdadero valor (externalidades). Con el transcurso de los años, el medio ambiente se consideró el sector del mercado donde las externalidades se producían con mayor frecuencia ${ }^{29}$. El primer paso lo dio PIGOU en 1920 que planteaba, entre otras cuestiones, la implantación de tributos (impuestos pigouvianos) sobre los agentes contaminantes para corregir las externalidades negativas ambientales. Todo ello a partir de su tratamiento de las divergencias entre los valores del producto marginal neto social y privado ${ }^{30}$. Por su parte, COASE ${ }^{31}$ rechazaba el intervencionismo estatal que propuso Pigou y defendía la internalización de los costos ambientales a través de la negociación privada entre los sujetos involucrados partiendo de la base que los costos de negociación son siempre cero. No obstante, tampoco deja totalmente de lado el

26 Morel (2000) p. 57.

27 La OCDE tiene dicho que estos tributos “...implican un precio que ayuda a asegurar que los contaminadores toman en cuenta los costos de su contaminación cuando adoptan decisiones de producción y consumo". OCDE (2001) p. 9. Asimismo, se trata de una práctica que “...lleva a una relocalización de los recursos según criterios de justicia y eficiencia”. OCDE (2001) p. 19.

28 OCDE (2001) p. 11. Tanto la OCDE como la European Environmental Agency (EEA) han señalado que este principio no encarna la idea de subsidio, sino la internalización de costos ambientales distribuidos entre el sector público y privado. OCDE (2001) p. 16 y EEA (2005) p. 40.

29 Yábar Sterling (2002) p. 45.

30 Pigou (1920).

31 Coase (1960). 
papel del Estado ya que su propuesta requiere que este asigne correctamente los derechos de propiedad ${ }^{32}$ entre la colectividad. Esta última postura es la que se conoce como "Teorema de Coase" 33 y se basa en un mundo tan perfecto como teórico en el que no existen costes de transacción, pero es sabido que en la realidad ello no funciona de esa manera y allí es cuando incluso sus propios partidarios dudan que la intervención estatal "proteja el medio ambiente peor que un sector privado que negocie entre sí unos derechos de propiedad correctamente definidos y asignados"34.

El Estado cuenta con una amplia gama de medidas para proteger el medio ambiente pero la elección de estas debe ser razonable y adecuada al objetivo propuesto. El dilema comienza preguntándose qué tipos de medidas se han de adoptar sobre determinadas conductas o actividades ${ }^{35}$. Tenemos medidas que buscan la erradicación total de una determinada conducta y otras solo pretenden desalentarla. En virtud de ello, el primer paso será determinar si es imprescindible que la conducta cuestionada no se lleve a cabo o si es tolerable pero dentro de ciertos niveles, por lo tanto, sería más conveniente morigerarla. Estamos ante un tema de política legislativa en donde habrá que analizar cuál es el resultado deseado para luego utilizar el mecanismo adecuado para alcanzarlo.

Si lo que se pretende es eliminar por completo una determinada actividad lo más razonable será optar por una norma restrictiva que sencillamente prohíba su realización. Para ello es imprescindible fijar paralelamente un conjunto de sanciones ( $v . g$. multas) que castiguen a los infractores. Nadie discutiría que sería irrazonable imponer un gravamen a quienes se dediquen a cazar especies en peligro de extinción, lo lógico es prohibir dicha actividad. Pero si estamos ante actividades que son tolerables pero que en un momento dado resulta conveniente su desaliento es más apropiado recurrir a instrumentos de mercado ${ }^{36}$. Entre estos instrumentos se encuentran los tributos ambientales ya que, sin prohibir las

\footnotetext{
32 Desde esta perspectiva la estructura de los derechos de propiedad debería poseer las siguientes características: universalidad (todos los recursos son de propiedad privada y sus títulos jurídicos están perfectamente fijados); exclusividad (todos los beneficios y costes que se derivan de la apropiación y el uso de los recursos se acumulan directa o indirectamente en su propietario); transferibilidad (todos los derechos de propiedad son trasladables desde su propietario a otros individuos mediante el intercambio voluntario sin costos de transacción) y fuerza vinculante (los derechos no se ven reducidos o limitados por otros individuos). Yábar STERLING (2002) pp. 4748.

33 El famoso nombre de "Teorema de Coase" en realidad se debe a STIGLER quien aplica la postura de COASE al problema ambiental figurándolo con la contaminación de un arroyo. Concretamente, el autor propone suponer que dicha contaminación mata peces y lo que se tiene que decidir es lo siguiente: ¿Es el valor de los peces perdidos mayor o menor que el valor del producto que origina la contaminación del arroyo? Se deduce que el problema debe ser considerado en su totalidad y marginalmente. STIGLER (1976).

34 Yábar Sterling (2002) pp. 48-49.

35 Cuando un país decide implementar una medida ambiental concreta debe revisar cuidadosamente todas las alternativas para alcanzar dichos objetivos. OCDE (2001) p. 10.

36 "Ya sea ejerciendo una influencia sobre los precios (a través de impuestos o incentivos), o estableciendo cantidades absolutas (comercio de derechos de emisión) o cantidades por unidad de producción, los instrumentos de mercado reconocen implícitamente que las empresas son diferentes entre sí y proporcionan por tanto una flexibilidad que puede reducir sustancialmente los costes de las mejoras del medio ambiente". LiBRO Verde (2007) p. 3.
} 
conductas, desmotivan su realización ${ }^{37}$. Sería el caso de los tributos ambientales que, por ejemplo, desincentiven el consumo desmesurado de agua potable o la compra de automóviles extremadamente contaminantes ${ }^{38}$. Para constatar el acierto de la medida adoptada no solo es importante que exista una adecuación de medios y fines (ex ante) sino también que se realice una evaluación posterior (ex post), ya que la medida adoptada en realidad depende de su virtualidad práctica ${ }^{39}$.

Visto así podría decirse que la aplicación de tributos ambientales implica, en última instancia, que quien paga estaría jurídicamente habilitado para contaminar, ya que son medidas permisivas que consienten la contaminación a quienes afronten el correspondiente gravamen, es decir a quienes paguen ${ }^{40}$. No se trata de una vía libre para contaminar sino más bien una licencia para hacerlo pero dentro de ciertos niveles (tolerables).

Para comprender la reflexión precedente es primordial recordar el concepto de "contaminar", ya que un acto contaminante no siempre implica la realización de un daño ambiental. Como vimos en el punto II.2.1, la contaminación ambiental requiere cualquier tipo de alteración negativa de las condiciones normales de la naturaleza. Por su lado, el término "daño ambiental" encarna la idea de una alteración no solo negativa sino también relevante para el medio ambiente ${ }^{41}$. La comparación de estas dos nociones nos dice, por un lado, que casi cualquier actividad humana resulta contaminante para el medio ambiente y, por el otro, que el daño ecológico consiste en una actividad contaminante relevante, al ser intolerable para la sociedad. En definitiva, no cualquier acto contaminante conlleva la realización de un daño ambiental y, por ende, su consecuente responsabilidad sino solo aquel que tenga una determinada relevancia.

No podemos finalizar este acápite sin referirnos a ciertos tributos, supuestamente ambientales, que gravan determinadas actividades económicas aduciendo daños ambienta-

37 En idéntico sentido se afirma que “...los tributos pueden actuar en la zona en que la contaminación resulta tolerada pero indeseable”. Herrera Molina (2000) p. 53.

38 En el caso del vertido de aguas servidas se ha afirmado que los impuestos y las tasas no solo financian al Estado, por su recaudación al tratarse de especias tributarias, sino que también implican un desaliento de conductas en ese sentido y simultáneamente incentivan a los contribuyentes a buscar alternativas menos contaminantes. EEA (2005) p. 41.

39 EEA (2005) p. 11. Para ello es necesario tener en cuenta al menos tres elementos: 1) los efectos de la medida ambiental; 2) la eficacia de la medida ambiental y 3) la relación costo-beneficio de la medida ambiental. EEA (2005) p. 11.

40 La justificación está dada por el hecho que contaminar en tales circunstancias no es un tipo de conducta que el ordenamiento jurídico intenta impedir, como ocurriría con una medida restrictiva, sino que simplemente se está intentando disuadir. CARRIó (1990) p. 265.

41 Solo a título de ejemplo podemos citar la normativa argentina, chilena y española. En Argentina la Ley 25.675 de 2002 considera al daño ambiental como "toda alteración relevante que modifique negativamente el ambiente, sus recursos, el equilibrio de los ecosistemas, o los bienes o valores colectivos" (art. 27, Ley 25.675 de 2002). En el ordenamiento jurídico chileno tenemos la Ley 19.300 de 1994 que se refiere al daño ambiental como " toda pérdida, disminución, detrimento o menoscabo significativo inferido al medio ambiente o a uno o más de sus componentes” (art. 2, inc. e), Ley 19.300 de 1994). En España la Ley 26 de 2007 lo define como "cualquier daño que produzca efectos adversos significativos en la posibilidad de alcanzar o de mantener el estado favorable de conservación de esos hábitat o especies. El carácter significativo de esos efectos se evaluará en relación con el estado básico, teniendo en cuenta los criterios expuestos en el anexo I" (art. 1.a), Ley 26 de 2007). 
les pero que del análisis de su hecho imponible se observaba la ausencia de una verdadera finalidad ambiental, dejando de lado al principio contaminador-pagador.

En España uno de los casos más emblemáticos al respecto lo encontramos en la Comunidad Autónoma de las Islas Baleares con el Impuesto sobre instalaciones que inciden en el medio ambiente, aprobado por la Ley 12/1991. Este tributo recaía sobre los titulares de elementos patrimoniales situados en el territorio de la Comunidad que estaban afectos a la realización de actividades que incidían sobre el medio ambiente (art. 2). Estos elementos eran cualquier tipo de instalación o estructura destinadas a las actividades de producción, almacenaje, transformación, transporte efectuado por elementos fijos y suministro de energía eléctrica y de carburantes y combustibles sólidos, líquidos o gaseosos y a las de comunicaciones telefónicas o telemáticas (art. 1.2). La base imponible estaba formada por el valor de los elementos patrimoniales afectos, que surgía de la capitalización al tipo de $40 \%$ del promedio de los ingresos brutos de explotación procedentes de la facturación del sujeto pasivo (arts. 7 y 8). El Tribunal Constitucional español (STC 289/2000) lo declaró inconstitucional sosteniendo lo siguiente: "no cabe considerar que el referido impuesto grave efectivamente la actividad contaminante cuando desconoce el impacto ambiental en que incurren los sujetos llamados a soportarlo, o lo que es lo mismo, la medida concreta en la que cada uno afecta al medio ambiente... Si lo efectivamente gravado fuese la actividad contaminante se habrían sometido a imposición todas aquellas instalaciones, cualquiera que fuese la clase de actividad a la que se hallasen afectas, que de alguna manera pudiesen atentar contra ese medio ambiente, buscando un efecto disuasorio o estimulante de la realización de conductas dañinas o protectoras del entorno ecológico en el que se desenvuelve la actividad”.

\section{Límites CUANTITATIVOS EN LOS TRIBUtOS AMBIENTALES A PARTIR DEL PRINCIPIO CONTAMINADOR-PAGADOR}

Uno de los debates sobre los tributos ambientales estriba en determinar cómo debería llevarse a cabo su cuantificación según el principio quien contamina paga. Cabría preguntarse si este principio impone alguna especie de límite económico a la hora de regular un gravamen ecológico. Algunos autores entienden que según dicho principio un tributo ambiental nunca debería superar alguno de los siguientes límites: los daños producidos, la utilidad del uso de los bienes ambientales y el costo de evitar la contaminación.

Por nuestra parte entendemos que el principio contaminador-pagador no tiene por qué limitar la cuantía del tributo y mucho menos a través de los parámetros indicados. Esta función en todo caso le corresponderá al principio de capacidad contributiva pero desde otra perspectiva que ya veremos. El sustento de nuestra postura parte de la ubicación de los tributos ambientales dentro de las diferentes dimensiones del principio de ciernes.

En primer lugar, hablar de los daños producidos implica en cierta forma reconocer que la realización del hecho imponible de un gravamen ecológico produce un daño ambiental, consideración que no suscribimos. Hemos visto que todo daño ambiental encarna necesariamente un acto de contaminación ecológica, pero no toda contaminación implica indefectiblemente el acaecimiento de un daño ambiental. En definitiva, atento que no corresponde técnicamente hablar de daño ambiental en el caso de los tributos ambientales, 
mal pueden tomarse como límite del gravamen los costos de un daño que en realidad no existe, o no debiera existir.

En segundo lugar, es realmente complicado determinar el valor económico de la utilidad del uso de los bienes ambientales, razón por la cual tampoco no lo percibimos como un parámetro adecuado.

En tercer lugar, tampoco parece servir el parámetro de los costos de evitar la contaminación. Ello es así ya que el tributo ambiental es un instrumento de disuasión de conductas y una forma de lograr este objetivo es justamente que al agente contaminante le resulte más oneroso realizar la actividad contaminante (pagando el gravamen) que invertir en mecanismos que permitan realizar la misma actividad pero evitando los resultados contaminantes y, por ende, la imposición. En consecuencia, la medida desalentadora será más eficiente cuando el costo del tributo sea superior al costo de evitar la contaminación.

\section{RECEPCIÓN DEL PRINCIPIO CONTAMINADOR-PAGADOR EN EL ORDENAMIENTO JURÍDICO ARGENTINO}

El ordenamiento jurídico argentino no fue indiferente al reconocimiento internacional del principio contaminador-pagador sino que lo fue plasmando en diferentes normas que regulaban cuestiones específicas ${ }^{42}$ o que ratificaban tratados y convenciones internacionales ${ }^{43}$. No obstante, su consagración definitiva se forjó luego de la reforma constitucional de 1994 que fue considerada un hito para el Derecho ambiental argentino al reconocer en la Carta Magna ${ }^{44}$ al medio ambiente como un bien jurídicamente protegido.

De esta manera la Argentina se adhirió a la corriente de "constitucionalización" de la protección del medio ambiente que se fue forjando en la última parte del siglo XX, iniciando un proceso de legislación en materia ambiental sin precedentes en el país ${ }^{45}$.

El texto constitucional de 1994 ofrece una referencia acotada y restringida del principio quien contamina-paga pero que luego fue ampliada por la Ley 25.765 de 2002. Con-

\footnotetext{
42 La Ley 22.190, del 11 de marzo de 1980, régimen de prevención y vigilancia de la contaminación de las aguas u otros elementos del medio ambiente por agentes contaminantes provenientes de los buques y artefactos navales, establecía que "...los propietarios y armadores de los buques o artefactos navales que hubieren ocasionado la contaminación, serán responsables, en forma solidaria y objetiva... del pago de los gastos que por la limpieza de las aguas o por cualquier otro servicio que como consecuencia del hecho hayan debido realizar el Comando en Jefe de la Armada, la Administración General de Puertos o cualquier otro organismo interviniente" (art. 14)

43 La Ley 24.292, del 12 de enero de 1994, que aprueba el Convenio Internacional sobre Cooperación, Preparación y Lucha contra la contaminación por Hidrocarburos de 1990, consagra expresamente que "el que contamina paga" como principio general de Derecho ambiental internacional.

44 En Chile no existe un reconocimiento constitucional expreso de este principio aunque existen algunas leyes específicas en las que lo recogen, como por ejemplo la Ley 18.916, del 19 de enero de 1990, Código Aeronáutico (art. 155). Asimismo, se apoya la idea que este principio también fue reconocido implícitamente en la Ley 19.300, del 9 de marzo de 1994. Bases generales del medio ambiente, ya que según el Mensaje Presidencial enviado al Congreso Nacional para impulsar el proyecto de Ley "se funda en la idea de que el particular que actualmente contamina, o que lo haga en el futuro, debe incorporar a sus costos de producción todas las inversiones necesarias para evitar la contaminación".

45 "Hasta la reforma, la normativa vigente estaba signada por la fragmentación. A partir de la reforma el enfoque holístico del tema y el mandato proteccionista se han hecho nítidos". RosatTi (2004) p. 25.
} 
cretamente, se establece que "el daño ambiental generará prioritariamente la obligación de recomponer, según lo establezca la ley” (art. 41, primer párrafo in fine, $\mathrm{CN}$ ). Al darle prioridad a la recomposición del daño ecológico se está reconociendo como primera medida la función reparadora y como medida subsidiaria, cuando aquel sea irreversible, a la función resarcitoria de la responsabilidad ambiental.

Casi diez años más tarde a la reforma constitucional de 1994 fue publicada la Ley 25.675, conocida como "Ley General del Medio Ambiente", en cuyo articulado se desarrolló con mayor profundidad el principio contaminador-pagador. Allí se consagró el "principio de responsabilidad" que puede asimilarse al principio contaminador-pagador. Este principio determina lo siguiente:

"El generador de efectos degradantes del ambiente, actuales o futuros, es responsable de los costos de las acciones preventivas y correctivas de recomposición, sin perjuicio de la vigencia de los sistemas de responsabilidad ambiental que correspondan" (art. 4, Ley 25.675 de 2002).

No cabe duda que la norma plasmó un reconocimiento integral y abarcador del principio de ciernes y que, por lo tanto, es un precepto legal que debe iluminar todo el sistema tributario ambiental del país.

\section{PRINCIPIO DE CAPACIDAD CONTRIBUTIVA}

\section{ORIGEN}

El principio de capacidad contributiva opera como un criterio propio del Derecho tributario y se encuentra consagrado en la mayoría de las constituciones de los países occidentales. En algunos casos el reconocimiento constitucional del principio es expreso ${ }^{46}$ y en otros es implícito. Este último supuesto sería, por ejemplo, el de Argentina, cuando se mencionan a "las demás contribuciones que equitativa y proporcionalmente establezca el Congreso de la Nación” o al prohibirse la confiscación (arts. 4 y 17, CN), o de Chile cuando la Constitución asegura a todas las personas "la igual repartición de los tributos en proporción a las rentas o en la progresión o forma que fije la ley, y la igual repartición de las demás cargas públicas" (art. 19, 20, CN).

Algunos autores coinciden en afirmar que el origen de la formulación de este principio se debe a Francesco GuICCIARDI, quien a principios del siglo XVI afirmaba que "dado que somos todos ciudadanos de un mismo Estado y que somos todos iguales, solo puede haber verdadera justicia o verdadera igualdad si los impuestos nos devuelven a todos al mismo nivel económico. Es necesario que nos tornemos tan iguales como la razón quiere que seamos" ${ }^{47}$. Aunque también se suele hablar de AdAm Smith ${ }^{48}$ y John StUART Mill ${ }^{49}$ como los formuladores de este principio.

\footnotetext{
46 Alemania (art. 28.3); Bolivia (art. 8.d); Brasil (art. 145.III.1); España (art. 31.1); Italia (art. 53); Panamá (art. 261); Paraguay (art. 181); Suiza (art. 127.2); Venezuela (art. 316), entre otras.

47 Duverger (1975) p. 28.

48 De Juano (1969) p. 401.

49 JaRACH (1989) pp. 11, 256 y ss.
} 
Más allá de quién fuera el primer autor en plantearlo, nadie duda en situarlo como uno de los pilares fundamentales del sistema fiscal, partiendo del postulado que los eventuales contribuyentes tienen medios limitados para hacer frente a sus necesidades públicas y privadas. La financiación de las cargas públicas debe repartirse entre los miembros de la comunidad según los medios que disponen ${ }^{50}$.

\section{NOCIÓN Y CONTENIDO}

Algunos autores lo han concebido no tanto como un principio sino más bien como un criterio para entender los principios de igualdad y generalidad ${ }^{51}$. Todos (generalidad) aquellos que reflejen idéntica (igualdad) capacidad contributiva están llamados a contribuir a las arcas del Estado. Visto así, la capacidad contributiva estaría en un plano secundario y a merced de los otros dos principios. Esta posición merece ciertos reparos ya que no sirve para explicar aquellos casos en los que existe igual capacidad contributiva pero por otras razones o principios constitucionales existe un tratamiento fiscal diferenciado ( $v . g$. beneficios fiscales).

Otros autores se ubican en el extremo opuesto al darle un papel estelar al principio. En este sentido afirman que "el criterio de igualdad, en esencia, se construye a lomos del de capacidad económica: que todos contribuyan en función de su capacidad para ello" 52 .

Nosotros entendemos que estamos ante un verdadero principio constitucional tributario autónomo que tiñe a todo el sistema tributario pero que siempre debe coordinarse con el resto de preceptos de la Constitución.

Desde hace tiempo que la doctrina mayoritaria ha ido configurando la noción de este principio a partir de una doble función: legitimadora y delimitadora.

Por un lado, cuando se habla de su función legitimadora se lo relaciona con el deber de solidaridad, en el sentido que la justificación constitucional del deber tributario no reside en una relación conmutativa entre el individuo y el Estado ${ }^{53}$ sino más bien en la solidaridad que posee cada miembro de la comunidad, por el solo hecho de pertenecer a ella ${ }^{54}$. "La justificación de la contribución al gasto público, no puede ser encontrada a partir de una concepción privatista, en una ventaja obtenida por el individuo de la actividad del ente público; en el fenómeno tributario se manifiesta un aspecto de la inserción del sujeto en la colectividad, para cuya subsistencia tiene el deber de aportar" 55 .

Por otro lado, su función delimitadora se refiere al poder legislativo y a su correspondiente potestad tributaria ejercida al momento de regular los tributos. Esto quiere decir que se garantiza a los contribuyentes que su deber de contribuir solo le será exigido en razón de un hecho indicativo de capacidad contributiva ${ }^{56}$. Es por ello que se lo entiende como una

50 Pérez de Ayala (2004) p. 74.

51 Jarach (1987) p. 884 y Ferreiro Lapatza (2006) p. 282.

52 Rozas Valdés (2011) p. 18.

53 Moschetti (1994) pp. 225-226.

54 Moschetti (1994) pp. 239-241.

55 Fedele (1971) p. 27.

56 Tesauro (2000) p. 59. 
guía para el legislador, quien debe procurar que el sistema tributario sea en su conjunto un reflejo de la capacidad económica global de los sujetos ${ }^{57}$.

Respecto a esta última función entendemos que al amparo de este principio los tributos ambientales nunca podrán afectar el mínimo vital de una persona, es decir los recursos que esta precisa para llevar adelante sus necesidades básicas. Es por ello que se concibe a la capacidad contributiva como aquella manifestación económica que supera los recursos que necesita el sujeto pasivo para cubrir sus necesidades elementales.

El problema que se deriva de lo anterior, y en el que no pretendemos ahondar en esta oportunidad, estriba en determinar cuál es el mínimo vital o las necesidades básicas de una persona. Solo adelantamos que estamos ante una cuestión de política legislativa que requiere de un análisis sociocultural enmarcado bajo unas condiciones de tiempo y lugar determinadas.

En resumen, este principio, junto al hecho de vivir en sociedad, legitima y justifica el pago de tributos por parte de los ciudadanos, por un lado, y limita las facultades legislativas tributarias del Estado en cuanto que no podrán legislarse y aplicarse gravámenes sobre quienes no cuenten con dicha capacidad, por el otro.

\section{EL PRINCIPIO DE CAPACIDAD CONTRIBUTIVA Y LOS TRIBUTOS AMBIENTALES}

La convivencia de los fines extrafiscales (tributos ambientales) con los principios constitucionales que rigen el sistema tributario es un tema que no ha pasado inadvertido para la doctrina y jurisprudencia; y el principio de capacidad contributiva es el que más debate ha generado ${ }^{58}$.

La relación entre los tributos ambientales y dicho principio nos plantea al menos dos inquietudes. La primera estriba en comprobar si estos gravámenes, marcados por una finalidad extrafiscal (ambiental), están sujetos al principio de capacidad contributiva como el resto de tributos. Y en caso de ser afirmativa, la segunda inquietud implica determinar cómo se aplica en la práctica este principio a los tributos ambientales.

Respecto a la primera inquietud la gran mayoría de la doctrina ${ }^{59}$ y jurisprudencia ${ }^{60}$ coincide en afirmar que este principio debe informar todo el sistema tributario. Esta tesitura comprende lógicamente a los gravámenes con fines ambientales, ya que "la equitativa distribución de la carga fiscal no puede sacrificarse para el logro de estos fines por muy elevados y atrayentes que estos sean" ${ }^{61}$. Pérez RoYo afirma que "el presupuesto del tributo...

\footnotetext{
57 Pérez Royo (2009) p. 58.

58 Sobre este punto es interesante el planteo de Lejeune ValCARCEL (1980) pp. 122 y ss.

59 VV.AA. (Sáinz de Bujanda, 1963, p. 262; Calvo Ortega, 1973, p. 22; Lejeune Valcárcel, 1980 , p. 118; Falcón y Tella, 1982, p. 383; Cors Meya, 1986, pp. 332-334; Pérez de Ayala, 2004, p. 78; Ferreiro Lapatza, 2006, p. 283; Pérez Royo, 2009, p. 60; Marín Queralt et al., 2010, p. 115; entre otros).

60 Sentencias del Tribunal Constitucional español 19/1987; 221/1992; 164/1995; 44/1996; 141/1996; 182/1997; 194/2000; entre otras. En la causa Díaz Vélez (1928) la Corte Suprema de Argentina deja sentado que al legislar sobre tributos ultrafiscales habrán de apreciarse "las facultades de los contribuyentes para soportar las cargas sociales", haciendo una clara referencia a la capacidad contributiva de los administrados.

61 Sainz de Bujanda (1963) p. 420.
} 
debe incorporar siempre un índice de capacidad económica, una aptitud para contribuir, aunque el tributo sirva, además, a otras finalidades"62.

Esta postura no ha estado exenta de críticas argumentando que en este tipo de figuras la protección del medio ambiente es un concepto ajeno a la capacidad económica como manifestación de riqueza que sujeta a gravamen las figuras tributarias tradicionales ${ }^{63}$. No obstante, como ya adelantamos, estas críticas son ciertamente minoritarias.

Pensémoslo de esta forma: si el ideal de los tributos con fines extrafiscales fuese lograr una recaudación nula o inexistente, podría pensarse que la capacidad contributiva poco tiene que hacer en estos gravámenes. Si no importa la recaudación, porque no interesa justamente recaudar, de poco sirven los límites para obtenerla. Pero estos gravámenes no funcionan así, de hecho ninguno lo hace. Todos los tributos gozan, en mayor o menor medida, de una finalidad recaudatoria y es por ello que la obligación de aportar a las arcas del Estado se ha de exigir en todo momento a partir de una manifestación económica de los contribuyentes.

Ello no implica desconocer que la presencia del principio de capacidad contributiva puede no ser tan evidente como en los tributos de finalidad puramente recaudatoria y que los gravámenes ecológicos también se sustentan en otros principios constitucionales no tributarios, como por ejemplo el principio contaminador-pagador ${ }^{64}$. La segunda inquietud planeada implica aplicar el mentado principio para ver de qué manera debe volcarse a tributos signados por una intencionalidad ambiental ${ }^{65}$. Existe una generalizada coincidencia en que el principio no desaparece en los tributos ambientales pero se presenta de una manera diferente que en otros $\operatorname{casos}^{66}$, es por ello que muchas veces habrá que realizar un análisis casuístico. Esta dosis de practicidad dificulta la tarea, ya que no es sencillo encontrar reglas o criterios que resistan la interminable casuística que puede darse en estos tipos de gravamen, pero ello no impedirá que intentemos dar una serie de pautas generales.

El legislador siempre debe procurar que los tributos ambientales sean concebidos respetando la capacidad contributiva de los sujetos pasivos; y desde ya adelantamos que es posible vincular dicha capacidad con la contaminación, la cuestión es cómo. Los indicios de capacidad contributiva de un tributo no se evidencian con la mera posesión o intercambio de riqueza, sino que existen ciertas actividades y bienes ligados con el aprovechamiento

62 Pérez Royo (2009) p. 59.

63 Martos García (2001) p. 55.

64 "La admisión de fines extrafiscales... no supone desconocer absolutamente las exigencias de la capacidad económica, sino únicamente limitarlas o matizarlas en función de otras finalidades". FALCón y TelLA (1995) p. 674.

65 "La doctrina más generalizada no se ha atrevido nunca a negar la virtualidad, en el tema de la extrafiscalidad, de la capacidad contributiva, pero admitiendo que precisamente por ser un tributo extrafiscal, la capacidad contributiva... podía ser tenida en cuenta en forma diferenciada en razón de los concretos efectos económicos o de otro tipo perseguidos. Pero no se han señalado, ni en la doctrina ni en el derecho positivo, aquellos límites concretos que en la utilización de la extrafiscalidad no se podían rebasar". Arzega ZubillaGa (2004) p. 4.

66 Baena Agullar (1995) pp. 12-13. 
ambiental que también pueden manifestar indicios de capacidad económica en el sujeto que las lleva a cabo ${ }^{67}$.

BaEna Aguilar señala que es posible crear tributos por la realización de actividades contaminantes, sobre la renta obtenida a través de ella o por la posesión de un patrimonio contaminante, ya que en todos estos casos se manifiesta, en principio, una cierta capacidad económica susceptible de imposición ${ }^{68}$. No obstante, hay que tener en cuidado de no caer en excesos y evitar que la preocupación por respetar la capacidad contributiva no nos lleve a relegar el carácter ecológico del gravamen. Para hablar de un verdadero tributo ambiental su estructura también debe responder al criterio de la capacidad contaminante del sujeto pasivo, consiguiendo así la prevención del daño ecológico que propugna el principio contaminador-pagador.

En consecuencia, se trata de crear un tributo ambiental sobre la realización de una actividad productiva contaminante, la renta obtenida en un proceso de producción industrial, el consumo o la circulación de productos contaminantes pues, todas ellas, en principio, devendrán en utilidades ${ }^{69}$. Es cierto que no siempre será posible detectar con claridad la capacidad contributiva que subyace de la realización de actividades o utilización de bienes contaminantes, pero ello no debe impedir que aquella sea localizada.

Acudimos nuevamente a la normativa tributaria española para dar un ejemplo de un tributo pretendidamente ambiental cuyo hecho imponible no respeta, en ciertos supuestos, la capacidad contributiva de los sujetos alcanzados. Concretamente nos referimos al Impuesto sobre el daño medioambiental causado por las instalaciones de transporte por cable, implementado por la Comunidad Autónoma de Aragón en la Ley 13/2005. La idea es gravar "la concreta capacidad económica que se manifiesta en determinadas actividades desarrolladas mediante la utilización de las instalaciones o elementos de dichos sistemas de transporte de personas, mercancías y bienes" (art. 14), dando a entender en este artículo que tales instalaciones o elementos debe ser efectivamente utilizados. No obstante, si bien más adelante se define al hecho imponible como el "daño medioambiental causado directamente por las instalaciones de transporte mediante líneas o tendidos de cable que se relacionan en el artículo 14" (art. 16.1), seguidamente la norma aclara que "se entenderá producido el daño medioambiental aun cuando las instalaciones y elementos del transporte descrito se encuentren en desuso o no hayan entrado en funcionamiento" (art. 16.2).

Si bien el impuesto no prescinde completamente del principio de capacidad contributiva (también alcanza al empleo efectivo de estas instalaciones) lo pasa por alto cuando además sujeta a las instalaciones y los elementos de transporte que estén en desuso, ya que no habría una manifestación de riqueza gravable. En estos supuestos la medida parece tener

\footnotetext{
67 Picciaredda y Selicato (1996) pp. 115-116.

68 Baena Aguilar (1995) p. 13. Por su parte, Rosembuj señala que "el hecho imponible tomará en cuenta la capacidad económica de la riqueza imponible en términos de aptitud real o potencial de contaminación y su fundamento es la relación de correspondencia, en razón de los efectos recíprocos entre el sujeto pasivo y obligado tributario... y el sector público, en razón de la protección del bien ambiental”. Rosembuj (1998) p. 14.

69 Luchena Mozo (2005) pp. 4 y 17.
} 
una naturaleza más sancionatoria que tributaria ${ }^{70}$. En este sentido PÁEZ MEdina sostiene que "si las instalaciones están en desuso o inactivas, no hay operación, conducta o actividad, valga la redundancia... y por tanto, tampoco una riqueza derivada de ellas que suponga para el legislador una "concreta capacidad contributiva manifestada" 71 . En definitiva, ningún tributo ecológico puede albergar un hecho imponible ajeno a todo tipo de manifestación económica del sujeto pasivo. De forma tal que, a riesgo de ser tachado de inconstitucional, el principio de capacidad contributiva siempre deberá estar presente para garantizar el límite inferior que marca el mínimo vital de cada administrado. A mayor abundamiento podemos decir que un tributo ambiental nunca debe alcanzar un hecho económicamente negativo o manifestaciones meramente potenciales y futuras de capacidad contributiva ${ }^{72}$. Una vez claro esto, su determinación queda librada al criterio del legislador dentro del ámbito de la política legislativa ${ }^{73}$.

\section{LÍMITES CUANTITATIVOS EN LOS TRIBUTOS AMBIENTALES A PARTIR DEL PRINCIPIO DE CAPACIDAD CONTRIBUTIVA}

Hablar de los límites cuantitativos que se derivan del principio de capacidad contributiva nos remite a su función delimitadora. Según esta ningún tributo (incluidos los ambientales) puede establecer una presión fiscal que vaya más allá del mínimo vital de los contribuyentes. Es decir que el gravamen no puede alcanzar los recursos indispensables que los sujetos necesitan para cubrir sus necesidades básicas. "Los fines no fiscales son plenamente admisibles con la estructura de los tributos, siempre y cuando respeten los mínimos necesarios exigidos por el principio de capacidad económica... al gravar auténticas manifestaciones de poder económico"74.

\section{RECEPCIÓN DEL PRINCIPIO DE CAPACIDAD CONTRIBUTIVA EN EL ORDENAMIENTO JURÍDICO ARGENTINO}

En nuestra Constitución, así como en la de Chile, no existe un reconocimiento expreso de este principio pero la mayoría de la doctrina sostiene que se encuentra reconocido de manera implícita en el artículo 4, cuando habla de "las demás contribuciones que equitativa y proporcionalmente" establezca el Congreso de la Nación, y en el artículo 17, en cuya parte final prohíbe todo tipo de confiscación ${ }^{75}$. Recordemos que el principio de capacidad contributiva es la contracara del principio de no confiscación, el cual sí goza de un reconocimiento constitucional explícito.

\footnotetext{
70 Algunos autores ponen en duda su naturaleza fiscal "[...] en la medida que confunde la denominada capacidad de contaminar con el daño medioambiental, pues este último concepto corresponde, más que al ámbito del sistema tributario, al contenido de la legislación sancionadora y sobre responsabilidad por los perjuicios causados en el medioambiente” Hermosilla Martín y Rubio Escobar (2008) pp. 756-757.

71 Páez Medina (2012) p. 448.

72 Vaquera García (1999) p. 104.

73 De Mita (2007) p. 97.

74 Vaquera García (1999) p. 103.

75 García Etchegoyen (2004) pp. 207 y ss.
} 
Por su parte, la Corte Suprema de Justicia de la Nación de Argentina (CSJN) hace tiempo que adoptó este principio como una garantía constitucional para los contribuyentes, destacando su estrecha vinculación con el principio de igualdad y la prohibición de regular impuestos confiscatorios. Mencionamos algunos precedentes emblemáticos:

En las causas Massoti de Busso (1974) y Gaviña (1948), la Corte señaló que la igualdad no se puede juzgar adecuadamente si ante todo no se considera la condición económica de las personas que lo soportan. En la causa López López (1991) la CSJN declaró que "...el mayor o menor deber de contribuir que corresponde a cada uno según su condición y la función de sus requisas en la vida social”. Finalmente, uno de los fallos más trascendentes lo constituye la causa Navarro Viola (1989). En dicha oportunidad la CSJN dijo que esta capacidad es indispensable como requisito de validez de todo gravamen y agregó que la afectación del derecho de propiedad resulta palmaria cuando la ley toma como hecho generador una exteriorización de riqueza agotada antes de su sanción. De esta manera se deja en claro que la capacidad contributiva debe ser real, efectiva y actual.

\section{CONCLUSIONES}

El presente trabajo intenta proponer una armoniosa convivencia y coordinación entre los principios contaminador-pagador y de capacidad contributiva cuando confluyen en el ámbito de un tributo ambiental y, a partir de ello, responder una serie de interrogantes prácticos relacionados con la creación y aplicación de dicho tributo.

La vinculación y convivencia entre ambos principios se puede plantear en términos simplificados de la siguiente forma: los tributos ambientales siempre deben guiarse por estos dos principios. Ninguno de ellos está por sobre el otro y que su coexistencia simultánea es incuestionable; ambos hacen a la esencia misma de estos gravámenes que son tan ambientales como fiscales.

Por un lado, los tributos ambientales tienen como principal objetivo desincentivar actividades o bienes contaminantes (finalidad ecológica). Esta finalidad está direccionada por la dimensión preventiva (subdimensión disuasoria) del principio contaminadorpagador. Un gravamen que se aparte de dicho principio y que, como consecuencia de ello, prescinda de su finalidad ecológica, sencillamente deja de ser un tributo ambiental. Es por ello que un tributo ambiental siempre debe tener en consideración a los objetivos ambientales $^{76}$.

Por otro lado, los gravámenes ecológicos pertenecen al género "tributo", con la particularidad que su finalidad recaudatoria queda relegada a un segundo plano. En virtud de ello, se encuentran alcanzados por los principios fiscales que se aplican a todo gravamen, entre los cuales tenemos al principio de capacidad contributiva, según el cual está vedado todo sometimiento fiscal más allá del mínimo vital de los administrados. Un tributo que no cumpla con los postulados mínimos del principio de capacidad contributiva pierde su legitimidad. El principio contaminador-pagador, si bien es útil y necesario para regular los

76 OCDE (2001) p. 10. 
tributos ambientales “...no resulta el criterio adecuado de reparto de la carga fiscal, en reemplazo o como si fuera el de capacidad económica"77.

A partir de ello podemos afirmar que los gravámenes ecológicos, por su naturaleza fiscal y ambiental, están llamados a respetar una doble capacidad en el sujeto pasivo: la capacidad contributiva y la capacidad contaminante ${ }^{78}$. Si se omite la primera ya no estamos ante un tributo y si se resigna la segunda ya no se trata de un gravamen con finalidad ecológica sino puramente recaudatoria.

En consecuencia de todo lo expuesto hasta aquí estamos en condiciones de responder los interrogantes planteados al comenzar el trabajo:

1) ¿Es técnicamente adecuado legislar un tributo ambiental cuyo hecho imponible grave conductas o bienes ecológicamente irrelevantes? No. Esto es así ya que la finalidad ecológica que define a los tributos ambientales exige gravar actividades o bienes que sean perjudiciales para el medio ambiente desmotivando así su realización o utilización. De no ser así simplemente nos encontramos ante un tributo con finalidad recaudatoria, pero no ecológica. Esto es lo que ocurrió por ejemplo con el Impuesto balear sobre las instalaciones que inciden en el medio ambiente, ya que solo se ocupó de gravar una manifestación de riqueza pero sin la necesaria connotación ambiental que debe tener un tributo de estas características.

2) ¿Es técnicamente adecuado legislar un tributo ambiental cuyo hecho imponible grave conductas o bienes ecológicamente relevantes pero el contaminador no goza de capacidad contributiva? No. Hemos dicho que todo gravamen, incluido los ambientales, en virtud del principio de capacidad contributiva tiene vedado alcanzar índices negativos de riqueza. En todo caso habrá que revisar la posibilidad de aplicar otro tipo de mecanismo de protección ambiental que no tenga naturaleza fiscal. Tal sería el caso del Impuesto aragonés sobre el daño medioambiental causado por la instalación de transportes por cable en donde existe un supuesto en el hecho imponible (desuso o abandono de instalaciones) en donde si bien existe una situación contaminante no se grava una exteriorización de riqueza, adoptando así una naturaleza más sancionatoria que fiscal.

3) ¿Qué límites que se derivan de los principios bajo análisis a la hora de regular un tributo ambiental? Si bien ambos principios condicionan la regulación de los tributos ambientales cuando hablamos de límites cuantitativos se diluye el papel del principio quien contamina paga. Este principio no tendría por qué limitar la cuantía del gravamen ecológico. Con esto no queremos decir que los tributos ambientales no tengan ninguna limitación cuantitativa de imposición sino que en última instancia esa función le corresponde al principio de capacidad contributiva. Según este último principio un tributo ambiental no debería sujetar fiscalmente una manifestación de riqueza superior a la que el contaminador precisa para cubrir sus necesidades básicas.

\footnotetext{
77 Rosembuj (2007) p. 10.

78 La capacidad del sujeto para ser sometido a la imposición debe resultar de la verificación de datos objetivos, como es el caso de la fuerza económica, entre otras; circunstancias que, trasladadas al fenómeno de la imposición ambiental, suponen que debe tenerse en cuenta la capacidad de contaminación. AmATUCCI (2002) p. 428.
} 


\section{BIBLIOGRAFÍA CITADA}

Aizega Zubillaga, Joxe M. (2001): La utilización extra-fiscal de los tributos y los principio de justicia tributaria (Bilbao, Universidad del País Vasco).

Amatucci, Andrea (2002): El ordenamiento jurídico financiero (Bogotá, Instituto Colombiano de Derecho Tributario).

Baena Aguilar, Ángel (1995): "Protección impositiva del medio natural”, CISS Noticias de la Unión Europea, No 122, 1995: pp. 11-24.

Calvo Ortega, Rafael (1973): "Las tasas de las Haciendas Locales: aspectos problemáticos”, Revista Crónica Tributaria, N 6, 1973: pp. 17-29.

Cámara de la Fuente, Macario (1993): "Derechos de propiedad y contabilidad medioambiental", Revista Española de Financiación y Contabilidad, Vol. XXII, No 75: p. 260.

Carrió, Genaro R. (1990): Notas sobre derecho y lenguaje (Buenos Aires, Abeledo-Perrot, cuarta edición).

COASE, Ronald (1960): “The problem of social cost", Journal of Law and Economics, No 3 (oct.): pp. 1-44;

Cors Meya, Xavier F. (1986): "Las tasas en el marco de un sistema tributario justo", Revista Española de Derecho Financiero, No 51: pp. 325-340.

DA Silva, Daniely Andressa (2012): "Tributos verdes: proteção ambiental ou uma nova roupagem para antigas finalidades?”, Revista Instituto de Derecho Brasilero, Año 1, no 8 : pp. 4993-5023.

De Juano, Manuel (1969): Curso de Finanzas y Derecho Tributario, T. I (Buenos Aires, Molachino).

De Mita, Enrico (2007): Principi di diritto tributario (Milano, Giuffrè Editore, cuarta edición).

Duverger, Maurice (1975): Finances Publiques (París, Presses Universitaires de France).

Espinoza Espinoza, Juan A. (2007): Derecho de la Responsabilidad Civil (Lima, Gaceta Jurídica, quinta edición).

European Environmental Agency (2005): "Effectiveness of urban wastewater treatment policies in selected countries: an EEA pilot study", EEA Environmental Issue Report, No $2 / 2005$

FALCÓN y Tella, Ramón (1982): "La finalidad financiera en la gestión del patrimonio", Revista Española de Derecho Financiero, Civitas, N³5: pp. 349-798.

Falcón y Tella, Ramón (1995): "Las medidas tributarias medio ambientales", en Esteve Pardo, José (Coord.), Derecho del medio ambiente y Administración local (Madrid, Diputación de Barcelona-Civitas).

FantozzI, Augusto (1998): Diritto tributario (Torino, Utet, segunda edición).

Fedele, Andrea (1971): "Corrispettivi di pubblici servizi, prestazioni imposte e tributi", Rivista di Diritto Financiero, II: pp. 2-32.

Ferreiro Lapatza, José J. (2006): Curso de derecho financiero español. Instituciones (Barcelona, Marcial Pons, vigésima quinta edición).

Fuentes Olivares, Flavio (1999): Manual de Derecho Ambiental (Valparaíso, Libromar, primera edición). 
Fullerton, Don (1996): "Why have separate environmental taxes?", Tax Policy and the Economy, Vol. 10: pp. 33-70.

Gallo, Franco (2011): Las razones del fisco. Ética y justicia en los tributos (Madrid-Barcelona-Buenos Aires, Marcial Pons).

García Etchegoyen, Marcos (2004): El principio de capacidad contributiva (Buenos Aires, Ábaco Rodolfo Depalma).

García López, Tania (2001): "Perspectiva jurídica del principio quien contamina paga”, Revista Dereito, Vol. 10, No 1: pp. 59-83.

STIGLER, George (1976): Teoría de los precios (Madrid, Alianza).

Hermosilla Martín, Ramón y Rubio Escobar, Pedro M. (2008): "La tributación medioambiental y los medios de transporte”, BeCKer, Fernando; CAZOrla, Luis María y Martínez-Simancas, Julián (Dir.), Tratado de Tributación Medioambiental, V. I. (Navarra, Thomson-Aranzadi) pp. 735-769.

Herrera Molina, Pedro. M. (2000): Derecho tributario ambiental (Barcelona-Madrid, Marcial Pons).

JARACH, Dino (1987): "En torno al principio de la capacidad contributiva en la Economía Financiera y el Derecho Tributario”, Revista La Información, T. LVI-noviembre 1987: p. 884.

JaRACH, Dino (1989): Finanzas públicas y derecho tributario (Buenos Aires, Cangallo).

Karan, Pradyumna P. (2005): Japan in the 21st Century: environment, economy and society (Kentucky, University Press of Kentucky).

Lejeune ValCarcel, Ernesto (1980): “Aproximación al principio constitucional de igualdad tributaria”, en Seis Estudios de Derecho Constitucional e Internacional Tributario (Madrid, Edersa).

Libro Verde (2007): Sobre la utilización de instrumentos de mercado en la política de medio ambiente y otras politicas relacionadas (COM-28.3.2007), 140 final \{SEC (2007) 388\}.

Luchena Mozo, Gracia M. (2005): "Las líneas actuales de gravamen en la tributación medioambiental”, Quincena Fiscal Aranzadi, No 18/2005: pp. 4-17.

Martín Queralt, José M.; Lozano Serrano, Carmelo; Tejerizo López, José M. y Casado Ollero, Gabriel (2010): Curso de derecho financiero y tributario (Madrid, Tecnos, vigésima primera edición).

Martos García, Juan J. (2001): “Tributación medioambiental y extrafiscalidad irregular. Análisis constitucional a propósito de la nueva redacción del art. 6.3 LOFCA y de la propuesta comunitaria de transformación del IVTM en un impuesto medioambiental", Quincena Fiscal Aranzadi, No 10/2011 (Estudio): pp. 35-72.

Morel, Ricardo D. (2010): Tributación ambiental. Herramienta de protección del medio ambiente (Buenos Aires, Osmar D. Buyatti).

Moschetti, Francesco (1994): "Profili generali”, en Amatucci, Andrea (Dir.), Tratatto di Diritto Tributario, V. I-1 (Padova, Cedam).

Muñoz, Macarena (2004): "El principio quien contamina paga, a la luz de la legislación medioambiental chilena”, Revista de Derecho Consejo de Defensa del Estado, No 12: pp. 159-186.

OCDE (2001): Environmentally Related Taxes in OECD Countries. Issues and Strategies.

OCDE (1995): Environmental principles and concepts. 
PÁez Medina, María E. (2012): La capacidad contributiva en los tributos medioambientales, Tesis Doctoral dirigida por María Ángeles Guervós Maíllo (Facultad de Derecho de la Universidad de Salamanca).

Pérez de Ayala, José L. (2004): Fundamentos de derecho tributario (Madrid, Editoriales de Derecho Reunidas, sexta edición).

Pérez Royo, Fernando (2009): Derecho financiero y tributario, Parte general (Pamplona, Thomson Reuters-Civitas, vigésima edición).

Picciaredda, Franco y Selicato, Pietro (1996): I tributi e l'ambiente. Profili ricostruttivi (Milano, Giuffrè Editore).

Pigou, Arthur (1920): The Economics of Wellfare (London, Mac Millan).

Pizarro, Ramón D. y Vallespinos, Carlos G. (1999): Instituciones de derecho privado. Obligaciones, T. 2 (Buenos Aires, Hammurabi).

Pizarro, Ramón D. y Vallespinos, Carlos G. (1999): Instituciones de derecho privado. Obligaciones, T. 5 (Buenos Aires, Hammurabi).

Rodríguez Muñoz, José Manuel (2004): "Los fines ultrafiscales de los tributos y su recepción en la nueva Ley General Tributaria", Nueva Fiscalidad, No 3-2004, marzo: pp. 9-59.

Rosatti, Horacio D. (2004): Derecho ambiental constitucional (Buenos Aires, Rubinzal-Culzoni).

Rosembuj, Tulio (1998): “Tributos ambientales", Fiscalidad Ambiental, abril-1998: p. 14.

Rosembuj, Tulio (2007): "Los impuestos ambientales en las comunidades autónomas", Quincena Fiscal, No 9/2007, Aranzadi: pp. 9-15.

Rosembuj, Tulio (2009): El impuesto ambiental (Barcelona, El Fisco).

Rozas Valdés, José A. (2011): "Nota preliminar", en Gallo, Franco, Las razones del fisco. Ética y justicia en los tributos (Madrid-Barcelona-Buenos Aires, Marcial Pons).

Rozo Gutiérrez, Carolina (2003): "Las funciones extrafiscales del tributo a propósito de la tributación medioambiental en el ordenamiento jurídico colombiano", Revista de Derecho (UASB-Ecuardor/CEN-Quito), No 1: pp. 179-199.

Sainz de Bujanda, Fernando (1963): Hacienda y Derecho, V. III (Madrid, Instituto de Estudios Políticos).

SALASSA Boix, Rodolfo (2013): "La finalidad extrafiscal de los tributos. Algunas notas sobre los tributos medioambientales", en Arroyo, Eduardo (Dir.), Estudios de Derecho Tributario (Córdoba, Advocatus y Universidad Nacional de Córdoba-Argentina) p. 186.

STIGLER, George (1976): Teoría de los precios (Madrid, Alianza).

Tesauro, Francesco (2000): Istituzioni di diritto tributario, V. 1, Parte generale (Torino, Utet, séptima edición).

Valenzuela, Rafael (1991): "El que contamina paga”, Revista de la CEPAL (Naciones Unidas. Comisión Económica para América), № 45: pp. 10-26.

VAndeKerckHove, Karen (1993): "The polluter pays principle in the European Community”, Yearbook of European Law, No 13: p. 204.

VAQUera García, Antonio (1999): Fiscalidad y medio ambiente (Valladolid, Lex Nova).

Varona Alabern, Juan E. (2010): "Extrafiscalidad irregular e imposición inmobiliaria", Quincena Fiscal Aranzadi (Aranzadi), No 1/2010: pp. 65-97. 
YÁbar Sterling, Ana (2002): "La temática ambiental en las doctrinas económicas del siglo XX”, en Yábar Sterling, Ana (Dir.), La protección fiscal del medio ambiente (MadridBarcelona, Marcial Pons) pp. 41-68.

\section{JURISPRUDENCIA CITADA}

Corte Suprema de Justicia de la Nación, "Díaz Vélez, Eugenio c/ Provincia de Buenos Aires s/ Inconstitucionalidad del adicional al impuesto inmobiliario", del 20 de junio de 1928, Fallos 151:359 (Argentina).

Corte Suprema de Justicia de la Nación, "Massoti de Busso, Ana c/ Provincia de Buenos Aires s/ Inconstitucionalidad del adicional al impuesto inmobiliario", del 7 de abril de 1974, Fallos 207:270 (Argentina).

Corte Suprema de Justicia de la Nación, "Gaviña, Mario c/ Provincia de Buenos Aires s/ Inconstitucionalidad del impuestos y contribuciones provinciales, del 4 de diciembre de 1948, Fallos 209:431 (Argentina).

Corte Suprema de Justicia de la Nación, "Navarro Viola de Herrera Vegas, Marta cl Estado Nacional s/ Acción de repetición", del 19 de diciembre de 1989, Fallos 312:2467 (Argentina).

Corte Suprema de Justicia de la Nación, "López López, Luis con Provincia de Santiago del Estero s/ Eximición de inversiones", del 15 de octubre de 1991, Fallos 314:1293 (Argentina).

STC 19/1987 (España).
STC 221/1992 (España).
STC 164/1995 (España).
STC 44/1996 (España).
STC 141/1996 (España).
STC 182/1997 (España).
STC 194/2000 (España).
STC 289/2000 (España).

\section{NORMAS CITADAS}

Constitución Nacional de la República Argentina de 1853 (última modificación: 1994).

Constitución Política de la República de Chile de 1980 (última modificación: 2014).

Ley 26, del 23 de octubre de 2007, Responsabilidad ambiental (España).

Ley 12, del 20 de diciembre de 1991, Impuesto balear sobre las instalaciones que inciden

en el medio ambiente (España).

Ley 13, del 30 de diciembre de 2005, Medidas fiscales y administrativa en materia de tributos cedidos y tributos propios de la Comunidad Autónoma de Aragón (España).

Ley 18.916, del 19 de enero de 1990, Código Aeronáutico (Chile).

Ley 19.300, del 9 de marzo de 1994, Bases generales del medio ambiente (Chile). 
Ley 22.190, del 11 de marzo de 1980, régimen de prevención y vigilancia de la contaminación de las aguas u otros elementos del medio ambiente por agentes contaminantes provenientes de los buques y artefactos navales (Argentina).

Ley 24.292, del 12 de enero de 1994, aprueba el Convenio internacional sobre cooperación, preparación y lucha contra la contaminación por Hidrocarburos de 1990 (Argentina).

Ley 25.675, del 27 de noviembre de 2002, Política ambiental nacional (Argentina). 